\title{
ALGORITHMA K-MEANS CLUSTERING STRATEGI PEMASARAN PENERIMAAN MAHASISSWA BARU UNIVERSITAS SATYA NEGARA INDONESIA
}

\section{Algorithma K-Means Clustering Strategy Marketing Admission Universitas Satya Negara Indonesia}

\author{
Riama Sibarani, riama_sarah@yahoo.com ${ }^{1)}$, Omby, ombyti@yahoo.com ${ }^{2)}$ \\ 1)2) Teknik Informatika /Fakutas Teknik, USNI
}

\begin{abstract}
$K$-Means is one of the non-hierarchical data grouping methods that seeks to partition existing data into two or more groups. This method partitions the existing data into groups so that the same characteristic data is entered into the same group and the different characterized data are grouped into another group. This study aims to produce an analysis that can cluster or categorize data of graduate students in 2016 and 2017 to make the campaign more targeted and targeted. This research mengklaster graduate student data with attribute address, majors and GPA into three Clusters based on distance (Euclidean). The data that is processed is the graduation data from 2016-2017. This study processed population data. Data processing using SPSS 21 IBM software. The process of clustering as much as 17 iterations with minimum distance between clusters is 6.47. The value of significance indicates that there are significant differences between clusterl, cluster and cluster 3 associated with the attributes in the study. Cluster results show that the address (area) of students come from South Jakarta, Tangerang and West Jakarta for Department of Informatics, Information Systems, Accounting, Manajamen. Department of Environmental Engineering, Manajeman comes from several regions and not grouped. The PSP and BDP departments are from Java, Sumater and other regions. GPA> 3.00 comes from South Jakarta.
\end{abstract}

Keywords: K-Means, Cluster, Iteration. Euclidean, Significant.

\begin{abstract}
ABSTRAK
K-Means merupakan salah satu metode pengelompokan data non-hirarki yang berusaha mempartisi data yang ada kedalam bentuk dua atau lebih kelompok. Metode ini mempartisi data yang ada ke dalam kelompok sehingga data berkarakteristik sama dimasukan kedalam satu kelompok yang sama dan data yang berkarakteristik berbeda dikelompokan kedalam kelompok yang lain. Penelitian ini bertujuan untuk menghasilkan suatu analisa yang dapat mengcluster atau mengelompokan data mahasiswa wisudawan tahun 2016 dan 2017 untuk membuat promosi menjadi lebih tertarget dan tepat sasaran. Penelitian ini mengklaster data mahasiswa lulusan dengan atribut alamat, jurusan dan IPK kedalam tiga Cluster berdasarkan jarak (Euclidean). Data yang diolah adalah data wisudawan tahun 2016-2017. Penelitian ini mengolah data populasi. Proses pengolahan data menggunakan software SPSS 21 IBM. Proses pengklasteran sebanyak 17 iterasi dengan jarak minimul antar cluster adalah 6,47. Nilai signifikansi menunjukkan terdapat perbedaanyang berarti antara cluster1, cluster dan cluster 3 yang berhubungan dengan atribut-atribut pada penelitian. Hasil Cluster menunjukkan bahwa alamat (daerah) mahasiswa berasal dari Jakarta Selatan, Tangerang dan Jakarta Barat untuk jurusan Teknik Informatika, Sistem Informasi, Akutansi, Manajamen. Jurusan Teknik Lingkungan, Manajeman berasal dari beberapa daerah dan tidak mengelompok. Jurusan PSP dan BDP berasal dari Jawa, Sumater dan daerah lain. IPK> 3,00 berasal dari Jakarta Selatan.
\end{abstract}

Kata Kunci: K-Means, Cluster, Iterasi. Euclidean, Signifikan 


\section{PENDAHULUAN}

Universitas Satya Negara Indonesia adalah lembaga pendidikan tinggi swasta berdiri sejak tahun 1985 . Visi Universitas adalah menghasilkan lulusan yang mudah mendapatkan pekerjaan dan mampu menciptakan lapangan pekerjaan (usni.ac.id). Saat ini Universitas Satya Negara Indonesia pempunyai 4 fakultas yaitu Fakultas Teknik, Fakultas Ekonomi, Fakultas ISIP dan Fakultas FPIK. Universitas Satya Negara Indonesia sudah melaksanakan wisuda 28 kali (usni.ac.id). Pada tahun 2016 wisudawan ke 27 jumlah wisudawan adalah 474 yang terdiri dari Fakultas teknik berjumlah 140, Fakultas Ekonomi 203, FIPK 18 dan ISIP 98 (Buku wisudawan 2016). Dan tahun 2017 wisudaw ke 28 Jumlah wisudawan adalah 576 terdiri dari Fakultas Teknik berjumlah 138, Fakultas Ekonomi 294, ISIP 23 dan FPIK 23 (Buku wisudawan 2017).

Berdasarkan peraturan Nomor 12 Tahun 2012 Pasal 73 Perguruan Tinggi menjaga keseimbangan antara jumlah maksimum mahasiswa dalam setiap Program Studi dan kapasitas sarana dan prasarana, Dosen dan tenaga kependidikan, serta layanan dan sumber daya pendidikan lainnya (UU RI 2012). Pada tahun 2016 jumlah mahasiswa yang diwisuda adalah 474 dan pada tahun 2017 jumlah mahasiswa yang diwisuda adalah 576 . Jumlah mahasiswa baru tahun akademik 2017/2018 sebanyak 1008. Agar jumlah mahasiswa baru dapat dipertahankan dan bahkan bertambah, maka Universitas harus membuat suatu strategi pemasaran yang efektif dan efisien berdasarkan data-data mahasiswa yaitu: alamat asal sekolah, jurusan. Data tersebut bertumpuk selama bertahun-tahun. Data tersebut perlu ditambang dan dikelompokkan berdasarkan alamat asal sekolah dan jurusan. Pengelompokan data dengan menggunakan K-Means Clustering. Algoritma K-Means merupakan salah satu metode data clustering non hirarki yang berusaha mempartisi data ke dalam bentuk satu atau lebih klaster. Data yang memiliki karakteristik yang sama berada dalam satu klaster dan data yang mempunyai karakteristik yang berbeda dikelompokkan dalam kelompokkan yang lain.

Berdasarkan uraian diatas masalah diindentifikasikan sebagai berikut: belum adanya penambangan data tentang alamat asal mahasiswa, jurusan dan Indeks Prestasi mahasiswa. Sehingga bagian pemasaran belum mengetahui klaster-klaster alamat asal, jurusan serta IPK para mahasiwa

Berdasarkan indetifikasi masalah yang telah diuraikan, maka masalah dalam penelitian ini dirumuskan sebagai berikut: Bagaimana menerapkan algorithma KMeans untuk menetukan klaster alamat asal, jurusan dan IP mahasiswa, berdasarkan data wisudawan tahun akademik 2016 dan 2017

Batasan pembahasan dalam penelitian ini adalah; Data yang diolah adalah data mahasiswa lulusan Universitas Satya Negara Indonesia tahun 2016 dan 2017.Metode yang digunakan adalah metode K- Means,Data diolah dengan menggunakan SPSS 21 IBM

Adapun tujuan dari penelitian ini adalah mengimplementasikan algorithma K-Means untuk mengetahui klaster alamat asal, jurusan dan IPK mahasiwa berdasarkan data wisuda tahun 2016-2017. Manfaat dari penelitian ini adalah untuk membantu bagian pemasaran Universitas Satya Negara Indonesia dalam melakukan promosi yang efektif dan efisisien.

Pemasaran adalah suatu proses sosial yang di dalamnya individu dan kelompok, mendapatkan apa yang mereka butuhkan dan inginkan dengan menciptakan, menawarkan dan secara bebas mempertukarkan produk yangbernilai dengan pihak lain (Kotler, 2008:87). Menurut Jefkins (2004:107). Angipora (2007:75) mengemukakan bahwa pemasaran dapat didefinisikan dalam dua pengertian dasar, yaitu dalam arti kemasyarakatan dan dalam arti bisnis. 
Dalam arti kemasyarakatan, pemasaran adalah setiap kegiatan tukar-menukar yang bertujuan untuk memuaskan keinginan manusia, sedangkan dalam arti bisnis, pemasaran adalah sebuah sistem dari kegiatan bisnis yang dirancang untuk merencanakan, memberi harga, mempromosikan dan mendistribusikan jasa serta barang-barang pemuas keinginan pasar

Kata algorism berasal dari nama penulis buku Arab yang terkenal, yaitu Abu Ja'far Muhammad ibnu Musa AlKhuwarizmi (Al-Khuwarizmi dibaca orang Barat menjadi algorism). Dalam bahasa Indonesia, kata algorithm diserap menjadi algoritma. (Munir, 2005). Algoritma adalah urutan logis langkah - langkah penyelesaian masalah yang disusun secara sistematis.

Data Mining sering disebut sebagai Knowledge Discovery in Database (KDD) yaitu suatu kegiatan yang mencakup pengumpulan, pemakain data historis untuk menemukan keteraturan, pola hubungan dalam set data yang berukuran sangat besar. Output dari data mining ini dapat digunakan untuk menentukan kebijakan atau keputusan di masa yang akan datang. Salah satu teknik yang dikenal dalam data mining yaitu: clustering. Pengertian keilmuan dalam data mining adalah pengelompokan sejumlah data atau objek dalam suatu cluater atau group, dimana satu obek data adalah anggota hanya satu cluster. Setiap data dalam suatu cluster memiliki kemiripan yang hampir sama dan berbeda dengan objek dalam cluster yang lain.

Data mining ini juga dikenal dengan istilah pattern recognition (Santosa, 2007). Data mining merupakan metode pengolahan data berskala besar oleh karena itu data mining ini memiliki peranan penting dalam bidang industri, keuangan, cuaca, ilmu dan teknologi. Secara umum kajian data mining membahas metodemetode seperti, clustering, klasifikasi, regresi, seleksi variable, dan market basket analisis (Santosa, 2007). Salah satu teknik yang dibuat dalam data mining adalah bagaimana menelusuri data yang ada untuk membangun sebuah model, kemudian menggunakan model tersebut agar dapat mengenali pola data yang lain yang tidak berada dalam basis data yang tersimpan. (Prasetyo E, 2012).

Cluster : Clustering merupakan suatu metode untuk mencari dan mengelompokkan data yang memiliki kemiripan karakteriktik (similarity) antara satu data dengan data yang lain. Clustering merupakan salah satu metode data mining yang bersifat tanpa arahan (unsupervised). Dalam data mining ada dua jenis metode clustering yang digunakan dalam pengelompokan data, yaitu hierarchical clustering dan non-hierarchical clustering (Santosa, 2007). Hierarchical clustering adalah suatu metode pengelompokan data yang dimulai dengan mengelompokkan dua atau lebih objek yang memiliki kesamaan paling dekat. Kemudian proses diteruskan ke objek lain yang memiliki kedekatan kedua. Demikian seterusnya sehingga cluster akan membentuk semacam pohon dimana ada hierarki (tingkatan) yang jelas antar objek, dari yang paling mirip sampai yang paling tidak mirip. Secara logika semua objek pada akhirnya hanya akan membentuk sebuah cluster. Metode nonhierarchical clustering justru dimulai dengan menentukan terlebih dahulu jumlah cluster yang diinginkan (dua cluster, tiga cluster, atau lain sebagainya). Setelah jumlah cluster diketahui, baru proses cluster dilakukan tanpa mengikuti proses hierarki. Metode ini biasa disebut dengan K-Means Clustering (Santoso, 2010).

Tahapan data mining terdiri dari: a).Pembersihan Data (Data Cleaning); Pembersihan data merupakan proses menghilangkan noise dan data yang tidak konsisten atau data tidak relevan. b). Integrasi Data (Data Integration): Integrasi data merupakan penggabungan data dari berbagai database ke dalam satu database baru. c). Seleksi Data (Data Selection): Data yang ada pada database sering kali 
tidak semuanya dipakai, oleh karena itu hanya data yang sesuai untuk dianalisis yang akan diambil dari database. d). Transformasi Data (Data Transformation): data diubah atau digabung kedalam format yang sesuai untuk diproses dalam data mining. e). Proses mining: Merupakan suatu proses utama saat metode diterapkan untuk menemukan pengetahuan berharga dan tersembunyi dari data. f). Evaluasi pola (Pattern Evalution): Untuk mengidentifikasi pola-pola kedalam knowlodge based yang ditemukan.

Data mining dibagi menjadi beberapa kelompokan berdasarkan tugas yang dilakukan yaitu: a).Estimasi; Model dibangun menggunakan record lengkap yang menyediakan nilai dari variabel target sebagai nilai prediksi. b).Prediksi; nilai dari hasil akan ada dimasa mendatang. Contoh prediksi dalam bisnis dan penelitian adalah prediksi harga daging dalam 3 bulan yang akan datang contoh algoritmanya: Linear Regression, Neural Network, Support Vector Machine. c).Klasifikasi: Mengklasifikasikan variable kategori dalam tinggi, sedang, rendah. Algortitma yang digunakan Naives Bayes, K-Nearst Neighbor, C4.5. d)Pengklusteran: pengelompokan record, pengamatan, atau memperhatikan dan membentuk kelas objek-objek yang memiliki kemiripan. Kluster adalah kumpulan record yang memiliki kemiripan satu dengan yang lainnya ketidak miripan dengan recordrecord dalam kluster lain. Contoh algoritmanya: K-Means, Fuzzy C-Means, K-Medoids. f).Asosiasi :Tugas asosiasi dalam data mining adalah menemukan atribut yang muncul dalam suatu waktu. contoh algoritmanya: Apriori.

K-Means Clustering merupakan salah satu metode data clustering nonhirarki yang mengelompokan data dalam bentuk satu atau lebih cluster/kelompok. Data-data yang memiliki karakteristik yang sama dikelompokan dalam satu cluster/kelompok dan data yang memiliki karakteristik yang berbeda dikelompokan dengan cluster/kelompok yang lain sehingga data yang berada dalam satu cluster/kelompok memiliki tingkat variasi yang kecil (Agusta, 2007).

\section{METODOLOGI PENELITIAN}

Menurut Santosa (2007), langkahlangkah melakukan clustering dengan metode $K$-Means adalah sebagai berikut:a). Pilih jumlah cluster $k$, pusat cluster diberi nilai awal dengan angka random. b). Alokasikan semua data/objek ke cluster terdekat. Kedekatan dua objek ditentukan berdasarkan jarak kedua objek tersebut. Demikian juga kedekatan suatu data ke cluster tertentu ditentukan jarak antara data dengan pusat cluster.Untuk menghiutng jarak semua data ke setiap tiitk pusat cluster dapat menggunakan teori jarak Euclidean yang dirumuskan sebagai berikut:

$$
D(i, j)=\sqrt{\left(X_{1 i}-X_{1 j}\right)^{2}+\left(X_{2 i}-X_{2 j}\right)^{2}+\ldots+\left(X_{k i}-X_{k j}\right)^{2}}
$$

dimana:

$D(i, j)=$ Jarak data ke $i$ ke pusat cluster $j ; X_{k i}=$ Data ke $i$ pada atribut data ke $k ; X_{k j}=$ Titik pusat ke $j$ pada atribut ke $k$.

d). Hitung kembali pusat cluster dengan keanggotaan cluster yang sekarang. Pusat cluster adalah rata-rata dari semua data/ objek dalam cluster tertentu atau menggunakan median dari cluster tersebut. e).Tugaskan lagi setiap objek memakai pusat cluster yang baru. Jika pusat cluster tidak berubah lagi maka proses clustering selesai. Atau, kembali ke langkah nomor 3 sampai pusat cluster tidak berubah lagi

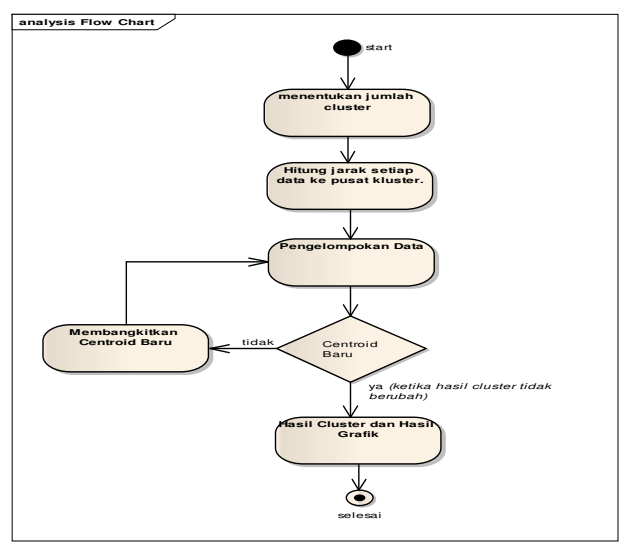

Gambar 1. Tahapan K-Means 
Suatu data akan menjadi anggota dari kluster ke-k apabila jarak data tersebut ke pusat kluster ke-k bernilai paling kecil jika dibandingkan dengan jarak ke pusat kluster lainnya. Gambar 1. Menunjukkan tahapan K-Means

Nilai pusat kluster yang baru dihitung dengan cara mencari nilai rata-rata dari data-data yang menjadi anggota pada kluster tersebut, dengan menggunakan rumus (2)

$$
C=\frac{\sum m}{n}
$$

$C=$ Centroid data,

$\mathrm{m}=$ Data yang termasuk dalam centroid data,

$\mathrm{n}=$ jumlah data yang menjadai anggota centroid tertentu.

Objek Penelitian adalah Universitas Satya Negara Indonesia berada di Jalan Arteri Pondok Indah No.11, Kebayoran Lama, RT.4/RW.2, RT.4/RW.2, Kby. Lama Utara, Kby. Lama, Kota Jakarta Selatan, Daerah Khusus Ibukota Jakarta 12240

Data-data yang digunakan pada penelitian data mahasiswa yang telah lulus tahun 2016-2017, sumber data adalah buku wisudawan . Data IPK diperoleh dari bagian BAKPSI. Data-data yang telah didapatkan pada tahap pengumpulan data kemudian dilakukan transformasi pada data-data yang berjenis data string :kota asal dan jurusan diinisialisasikan ke dalam bentuk data ordinal dan nominal. Pengolahan data ini menggunakan teoriteori dari data mining dengan algoritma $K$ Means Clustering atau yang lebih spesifik lagi algoritma $K$-Means Clustring. Dengan metode $K$-Means Clustering ini, data yang diperoleh dikelompokkan berdasar kemiripan karakteristik dari setiap data, sehingga dapat ditemukan informasi yang tersembunyi dari data-data tersebut. Untuk pengolahan data digunakan software SPSS IBM

Untuk melakukan inisialisasi kota asal dilakukan dengan langkah-langkah sebagai berikut: a). Pada data kota asal terlebih dulu dilakukan pembagian wilayah yang menjadi beberapa bagian wilayah, yaitu: wilayah DKI Jakarta, Wilayah Bogor dan sekitarnya serta wilayah Tangerang dan sekitarnya. b).Kemudian wilayah-wilayah tersebut diurutkan dari yang terbesar berdasarkan frekuensi mahasiswa yang berasal dari wilayah tersebut.

Iterasi dilakukan sampai beberapa kali proses. Iterais akan berhenti jika tidak ada lagi data yang berpindah dari klaster satu ke klaster lain. Hasil akhirnya ditemukan hasil final klaster center.

\section{HASIL DAN PEMBAHASAN}

Dengan menggunakan bantuan software SPSS 21 IBM, diperoleh output sebangai berikut : Tabel 1. initial Cluster menunjukkan pada tahapan awal terbentuk 3 buah cluster. Kemudian metode K-Mean Cluster akan menguji dan melakukan iterasi untuk rekolasi data hingga ditemukan tidak ada lagi objek yang berpindah claster.

\section{Tabel 1. Initial Cluster Centers}

\begin{tabular}{|l|l|l|l|}
\hline \multirow{2}{*}{} & \multicolumn{3}{|l|}{ Cluster } \\
\cline { 2 - 4 } & 1 & 2 & 3 \\
\hline Zscore(jurusan) & -.14071 & 1.38530 & .24079 \\
Zscore(alamat) & -1.32583 & -2.37515 & 3.92078 \\
Zscore(ipk) & -4.53339 & 2.10417 & 1.10298 \\
\hline
\end{tabular}

Hasil dari K-Means adalah final Cluster Center, pada table 2 yang berisi 3 klaster yang membagi data mahasiswa berdasarkan alamat, jurusan dan IPK. Jarak masing-masing cluster terhadap cluster lain.

Table 2 Distances between Final Cluster Centers

\begin{tabular}{|l|l|l|l|}
\hline Cluster & 1 & 2 & 3 \\
\hline 1 & & 2.518 & 1.553 \\
2 & 2.518 & & 2.411 \\
3 & 1.553 & 2.411 & \\
\hline
\end{tabular}


Jarak Klaster 1 dan klaster 3 sangat dekat, dan mempunyai kesamaan yang dekat jika dibandingkan dengan sementara klaster 2 Jumlah anggota/ data setiap klaster ditunjukkan pada table 3:

Tabel 3. Number of Cases in each Cluster

\begin{tabular}{|ll|l|}
\hline Cluster & 1 & 330.000 \\
& 2 & 209.000 \\
& 3 & 475.000 \\
Valid & & 1014.000 \\
Missing & & .000 \\
\hline
\end{tabular}

Pada cluster 1, Jurusan Teknik Informtika, Sistem Informasi, Manajeman Informatika lebih dominan di daearah Jakarta Selatan, Tangerang, dan Jakarta Barat. Dengan IPK tertinggi berada di Jakarta Selatan. Jurusan IKOM dan IHI dominan berasal dari Jakarta Barat dan Tangerang. Pada Cluster 2, Akuntansi dan Manajemen dominan berasal dari Jakarta Barat dan Tangerang. Sementara jurusan yang lain lebih menyebar dari beberapa daerah.IPK tertinggi berasal dari Jakarta Barat. Pada Cluster 3, Jurusan Teknik Informatika dominan berasal dari Jakarta Selatan, Tangerang dan Jakarta Pusat, Jurusan PSP dan BDP berasal dari luar Sumatra dan luar Jawa.

\section{SIMPULAN}

Simpulan

Metode K -Means telah berhasil mengelompokkan data alamat, jurusan dan IPK mahasiswa. Hasil cluster tersebut adalah sebagai berikut:

Cluster 1, daerah pemasaran yg sangat potensial untuk jurusan tekni informatika, system infromasi, akutansi, manajeman, IHI dan IKOM selain Jakarta Selatan adalah Tangerang dan Jakarta Barat. Jurusan PSP dan BDP bersal dari luar DKI. IPK $>3,00$ berasal dari Jakarta Selatan .

Cluster 2, daerah pemasaran yang potensial untuk jurusan teknik informatika adalah Jawa dan Sumatera. Untuk jurusan Sistem informasi, AKutansi, Manajemen, IHI dan
IKOM adalah Jakarta Selatan, tagerang, Jakarta Barat dan dan Jakarta Pusat. IPk $>3,00$ berasal dari Jakarta Selatan.

Cluster 3. Jurusan Teknik Lingkungan, BDP, PSP, MI berasal dari daerah jawa, Sumatera dan lain-lain. Daerah-daerah potensil di Clsuter 3 adalah Jakarta selatan, Tangerang dan Jakarta Barat.

\section{Saran}

Berdasarkan hasil penelitian dan kesimpulan penulis menyarankan agar bagian pemesaran dapat mempertibangkan dareah-daerah atau kota-kota yang menjadi daerah yang potensial untuk dikunjungi.

\section{DAFTAR PUSTAKA}

[1] Agusta, Y. 2007. K-means - Penerapan, Permasalahan dan Metode Terkait. Jurnal Sistem dan Informatika Vol. 3 (Februari 2007): 47-60.

[2] Hidayat, T., dan Istiadah, N. 2011. Panduan Lengkap Menguasai SPSS 19 untuk Mengolah Data Statistik Penelitian. Jakarta: Media Kita.

[3] Hair, J.F. Jr. Anderson, R.E. Tatham, R.L., dan Black W. C. (1992). Multivariate Data Analysis, Fifth edition. New Jersey: Prentice Hall.

[4] Lattin, J., carrol, D., dan green, P. (2003). Analying Multivariate Data. United State of America: Thomson Learning

[5] Myamoto, S and Agusta, Y (1995). Agorithm of Hard C-Means Clastein using KernelFunnction inSupport Vectro machines, Journal of Advnced Computational Intellingence and Inttelingent Informatics, vol 7. No. 1 pp 25-30

[6] Tahta Alfina, dkk: Analisa Perbandingan Metode HierarchicalClustering, K-means dan Gabungan Keduanya dalam Cluster Data(Studi kasus : Problem Kerja Praktek Jurusan Teknik Industri, Fakultas Teknologi Industri, Institut 
Teknologi Sepuluh Nopember (ITS), JURNAL TEKNIK ITS Vol. 1, (Sept, 2012) ISSN: 2301-9271, JurusanTeknik Industri ITS)

[7] Santoso, S. 2010. Statistik Multivariat. Jakarta: Elex Media Komputindo.

[8] Santosa, B. 2007. Data Mining: Teknik Pemanfaatan Data untuk Keperluan Bisnis. Yogyakarta: Graha Ilmu.

[9] Supranto, J. M.A. 2000. Statistik: Teori dan Aplikasi Edisi Keenam. Jakarta: Erlangga 